\section{Aplikasi e-diary DM sebagai alat monitoring manajemen selfcare pengelolaan diet pasien DM}

NURSCOPE

Jurnal Keperawatan dan Pemikiran IImiah Luawo, H.P., Sjattar, E.L., Bahas, B., Yusuf, S., dan Irwan, A.M. (2019). Aplikasi e-diary DM sebagai alat monitoring manajemen selfcare pengelolaan diet pasien DM.

Nurscope: Jurnal Keperawatan Pemikiran IImiah.

5(4).32-38

\author{
Herman Priyono Luawo ${ }^{1}$, Elly Lilianty Sjattar ${ }^{2}$, Burhanuddin Bahar ${ }^{3}$, Saldy Yusuf ${ }^{4}$, Andi Masyitha Irwan ${ }^{5}$ \\ ${ }^{1}$ Mahasiswa Pasca Sarjana Programs Studi Magister Ilmu Keperawatan Universitas Hasanuddin \\ 2,4,5 Dosen Pasca Sarjana Programs Studi Magister Ilmu Keperawatan Universitas Hasanuddin \\ ${ }^{3}$ Dosen Fakultas Kesehataan Masyarakar Universitas Hasanuddin
}

\begin{abstract}
Abstrak
Pendahuluan : Penatalaksanaan DM sangat penting dilakukan, upaya tersebut dapat melalui keterlibatan langsung penderita melalui program manajemen perawatan atau self care management. Tujuan : Mengetahui hasil monitoring aplikasi e-diary tehadap pegelolaan diet pasien diabetes mellitus. Metode : Menggunakan metode quasi eksperimen dengan rancangan pre post test with control group design, analisa data dilakukan dengan uji Wilcoxon dan Mann Whitney. Hasil : penelitian menujukkan bahwa terdapat pengaruh 75,9\%, penerapan e-diary memberikan kontribusi signifikan terhadap manajemen selfcare ( $P$ value=0,000). Pada kelompok intervensi sebelum diterapkan e-diary adalah 7,13 (SD 0,756), sedangkan sesudah dilakukan intervensi diperoleh nilai rata-rata pengeloaan diet sebesar 7,80 (SD 0,561) disimpulkan bahwa. Hasil tersebut menunjukkan adanya peningkatan skor rata-rata pengelolaan diet pada pasien DM sebesar 0,80 . Hasil analisis uji Wilcoxon Rank Test diperoleh nilai $p$ value 0,006 . Penerapkan e-diary pada pasien diabetes militus secara bermakna dan signifikan efektif dalam meningkatkan manajemen selfcare pengelolaan diet pada pasien diabetes militus.
\end{abstract}

Kata Kunci : Diabetes Militus, e-Diary, Manajemen Selfcare, Pengelolaan Diet

Application E-Diary Of DM as a Monitoring Tool Management Self Care : Diet Management Patients of DM

Abstract

Introduction: Management of DM is very important, patients can go through a direct program through a care management program or self-care management. Objective: To find out the results of monitoring e-diary applications for managing diabetic patients' diabetic diet. Method: Using a quasi-experimental method with pre-post-test design with a control group design, the data were analyzed using Wilcoxon and Mann Whitney tests. Results: The study showed that there was an influence of $75.9 \%$, the application of e-diary gave a significant effect on the management of self care ( $P$ value $=0,000)$. The mass group before applying e-diary was 7.13 (SD 0.756), while after the intervention was obtained the average dietary management was 7.80 (SD 0.561) conditioned. These results indicate an average increase in average diet management in DM patients by 0.80. Wilcoxon Rank Test results obtained p value of 0.006 . The application of e-diary to diabetic patients is significant and significant to improve self-care management in patients with diabetes mellitus.

Keywords : Diabetes Mellitus, e-diary, Self-care management, Diet Management

Corresponding Author:

Herman Priyono Luawo, Program Studi Magister Ilmu Keperawatan Universitas Hasanuddin, Jl. Perintis Kemerdekaan No. 10 Tamalanrea Makassar. Kode Pos : 90245, E-mail: Hermanluawo18@gmail.com 


\section{PENDAHULUAN}

Diabetes Mellitus (DM) adalah penyakit kronis yang kompleks yang memerlukan perawatan medis terus menerus dengan strategi pengurangan risiko multifaktorial luar kendali glikemik.Pendidikan manajemen diri pasien saat divonis dan dukungan sangat penting untuk mencegah komplikasi akut dan mengurangi risiko komplikasi jangka panjang (American Diabetes Association (ADA), 2015)

Penatalaksanaan secara umum Penderita DM dalam konsensus Penatalaksanaan dapat di tempuh melalui beberapa program jangka pendek dan program jangka panjang Untuk mencapai hal tersebut dapat dilakukan dengan edukasi, Terapi Nutrisi Medis, Latihan jasmani, Terapi farmakologis (PERKENI, 2015) Self-care menurut Orem berfokus pada bagaimana meningkatkan kemampuan klien untuk berperilaku yang dapat mempengaruhi kesehatannya. Kemampuan ini dilakukan sendiri oleh klien yang bertujuan untuk meningkatkan status kesehatan (Sousa, Hartman, Miller, \& Carroll, 2009)

Salah satu cara yang dapat dikembangkan untuk mendukung pelaksanaan selfcare manajemen diantaranya yaitu dengan memanfaatkan teknolgi yang sedang berkembang saat ini berupa aplikasi berbasis android. Aplikasi yang menggunakan smartphone sebagai salah satu sarana dalam memudahkan penerapan. Semua aktivitas selfcare manajemen dapat dimasukan kedalam program berbasis android diantaranta pengelolaan diet, latihan fisik, pengontrolan gula darah dan pengobatan diabetes militus. Peneliti saat ini berupaya untuk menciptakan aplikasi berbasis android dengan harapan dapat mempermudah selfcare manajemen pada pasien diabetes militus utamanya dalam pengelolaan diet.

Hasil penelitian (Prasetyo, 2016) tentang aplikasi perhitungan kebutuhan zat gizi pada penyakit diabetes mellitus berbasis android menunjukkan bahwa aplikasi perhitungan kebutuhan zat gizi pada penyakit diabetes melitus mendapat respon yang baik sehinnga dapat mempermudahkan kinerja ahli gizi untuk menghitung kebutuhan zat gizi. Dibuktikan dengan hasil riset menggunakan kuisoner yaitu $87 \%$ menilai baik aplikasi tersebut. Penelitian bertujuan mengembangkan aplikasi e-Diary yang berbasis android untuk mengevaluasi manajemen selfcare dalam memonitoring pegelolaan diet pasien diabetes mellitus. Aplikasi e-diary merupakan aplikasi android yang dipasangkan pada subjek penelitian yang sebelumnya telah di ketahui kemampuan Manajemen Selfcare nya melalui kuisioner.

\section{METODE}

Jenis penelitian adalah quasi eksperimen dengan rancangan pre post test with control group design yaitu penelitian yang dilakukan dengan mengelompokkan sampel menjadi dua kelompok dimana satu kelompok mendapatkan intervensi sedangkan kelompok satu tidak mendapatkan intervensi (Sudigdo Sastroasmoro, 2015). Penelitian ini dilaksanakan di Poliklinik Diabetes Mellitus RSUD Prof. Dr. H. Aloei Saboe Kota Gorontalo. Waktu penelitian dilaksanakan dari bulan November 2017 sampai dengan bulan Maret 2018. Populasi dalam penelitian ini sejumlah 130 pasien, setelah memenuhi kriteria didapatkan 30 pasein yang terdistribusi pada kelompok intervensi dan kelompok control.

Sampel dibagi dalam dua kelompok yaitu kelompok intervensi dan kelompok kontrol. Untuk penetapan kelompok intervensi dan kelompok kontrol dilakukan teknik random assignment. Simple random dilaksanakan pada responden yang tercatat di Polikliknik Diabetes Rumah Sakit Prof H. Aloei Saboe Kota Gorontalo dan telah memenuhi Kriteria. Setelah ditetapkan kelompok intervensi maupun kontrol, diukur selfcare manajemen dengan menggunakan kuisioner. Setelah diperoleh hasilnya kemudian intervensi aplikasi e-diary : Pengelolaan diet dilakukan khusus pada kelompok intervensi sedangkan kelompok kontrol tidak mendapat perlakuan. intervensi aplikasi e_diary ; Pengelolaan dilaksanakan oleh peneliti. Program ini dilaksanakan selama 2 minggu. Setelah program mentoring selesai maka dilakukan pengukuran akhir untuk masing-masing kelompok dan disimpulkan apakah terdapat perbedaan selfcare manajemen dalam Pengelolaan diet antara kelompok intervensi dan kelompok kontrol. 
Setelah mendapat rekomendasi Persetujuan Etik dengan Nomor : 1064/H4.8.4.5.31/PP36-KOMETIK/2017 yang didapatkan dari Komite Etik Penelitian Kesehatan RSPTN Universitas Hasanuddin, peneliti melakukan langkah selanjutnya yakni pengolahan data. Untuk mengetahui perbedaan selfcare manajemen antara kelompok intervensi dan kelompok kontrol dianalisa dengan Uji Wilcoxon dan Mannwhitney.

HASIL

Tabel 1.

Distribusi frekuensi karekteristik pasien diabetes melitus kelompok intervensi dan Kontrol di Poliklinik diabetes RSUD Prof Dr. Aloei Saboe Kota Gorontalo

\begin{tabular}{|c|c|c|c|c|}
\hline Kelompok & No & Karakteristik & $\begin{array}{c}n \\
(15)\end{array}$ & Frekuensi \\
\hline \multirow[t]{12}{*}{ Intervensi } & 1 & Jenis kelamin & & \\
\hline & & - $\quad$ Laki-laki & 3 & 20 \\
\hline & & - $\quad$ Perempuan & 12 & 80 \\
\hline & 2 & Pendidikan & & \\
\hline & & - SMA & 9 & 60 \\
\hline & & - $\quad$ Sarjana & 6 & 40 \\
\hline & 3 & Status pekerjaan & & \\
\hline & & - $\quad$ Tidak bekerja & 8 & 53,3 \\
\hline & & - Bekerja & 7 & 46,7 \\
\hline & & Karakteristik & Mean & Min-Max \\
\hline & 4 & Umur & 53,80 & $39-72$ \\
\hline & 5 & Lama menderita DM & 5,67 & $2-13$ \\
\hline \multirow[t]{13}{*}{ Kontrol } & & Karakteristik & $\begin{array}{c}n \\
(15)\end{array}$ & Frekuensi \\
\hline & 1 & Jenis kelamin & & \\
\hline & & - Laki-laki & 5 & 33,7 \\
\hline & & - $\quad$ Perempuan & 10 & 66,7 \\
\hline & 2 & Pendidikan & & \\
\hline & & - SMA & 10 & 33,3 \\
\hline & & - Sarjana & 5 & 66,7 \\
\hline & 3 & Status pekerjaan & & \\
\hline & & - Tidak bekerja & 9 & 60 \\
\hline & & - Bekerja & 6 & 40 \\
\hline & & Karakteristik & Mean & Min-Max \\
\hline & 4 & Umur & 52,93 & $42-68$ \\
\hline & 5 & Lama menderita DM & 6,27 & $2-12$ \\
\hline
\end{tabular}

Untuk kelompok intervensi karakteristik responden diperoleh data pasien pada kelompok intervensi ratarata berumur 53,80 tahun dimana umur terendah 39 tahun dan tertinggi 72 tahun serta sebagian besar berjenis kelamin perempuan (80\%). Pasien sebagian besar berpendidikan SMA (60\%) dan berstatus tidak bekerja (53,3\%) serta lama menderita diabetes militus rata-rata 5,67 tahun dimana lama DM terendah 2 tahun dan tertinggi 13 tahun. Pada kelompok kontrol karakteristik responden diperoleh data pasien pada kelompok kontrol rata-rata berumur 52,93 tahun dimana umur terendah 42 tahun dan tertinggi 68 tahun serta sebagian besar berjenis kelamin perempuan $(66,7 \%)$. Pasien sebagian besar berpendidikan SMA $(66,7 \%)$ dan berstatus tidak bekerja (60\%) serta lama menderita diabetes militus rata-rata 6,27 tahun dimana lama terendah 2 tahun dan tertinggi 12 tahun 
Tabel 2.

Analisis Kesetaraan Usia, lama menderita DM dan manajemen selfcare pada pasien diabetes melitus di Poliklinik diabetes RSUD Prof. dr. H. ALoei Saboe Kota Gorontalo $(n=30)$

\begin{tabular}{llccccc}
\hline & Variable & Kelompok & Rerata & SD & P value & $\mathbf{n}$ \\
\hline \multirow{2}{*}{ Usia } & Intervensi & 53,80 & 9,62 & \multirow{2}{*}{0,111} & \multicolumn{1}{c}{15} \\
\cline { 2 - 4 } & Kontrol & 52,93 & 6,59 & & 15 \\
\hline \multirow{2}{*}{ Lama DM } & Intervensi & 64 & 3,02 & \multirow{2}{*}{0,287} & 15 \\
\cline { 2 - 4 } & Kontrol & 54,13 & 2,35 & & 15 \\
\hline Manajemen selfcare & Intervensi & 6,27 & 3,67 & 0,698 & 15 \\
\hline
\end{tabular}

Berdasarkan tabel 2 dapat dijelaskan bahwa untuk usia responden dapat disimpulkan kedua kelompok intervensi dan kelompok kontrol mempunyai varian yang sama $(P=0,111)$. Demikian pula pada lama menderita $D M$ juga mempunyai varian yang sama $(P=0,287)$ dan pada manajemen selfcare juga mempunyai varian sama $(P=0,698)$.

Tabel 3.

Skor rata-rata pengelolaan diet pada pasien DM sebelum dan sesudah pada kelompok intervensi dan kelompok Kontrol di Poloklinik diabetes RSUD Prof Dr. Aloei Saboe Kota Gorontalo

\begin{tabular}{llcccc}
\hline Kelompok & Pengelolaan Diet & Mean & $\begin{array}{c}\text { Min- } \\
\text { max }\end{array}$ & SD & $\begin{array}{c}\text { P } \\
\text { value }\end{array}$ \\
\hline Intervensi & sebelum & 7.13 & $6-8$ & 0,756 & \multirow{2}{*}{0,006} \\
& sesudah & 7.80 & $6-8$ & 0,561 & \\
\hline Kontrol & Sebelum & 6.93 & $6-8$ & 0.884 & \multirow{2}{*}{0,157} \\
& Sesudah & 7.07 & $6-9$ & 0.799 & \\
\hline
\end{tabular}

wilcoxon signed rank test

Berdasarkan tabel tersebut diperoleh nilai rata-rata pengelolaan diet pada pasien DM kelompok intervensi sebelum diterapkan e-diary adalah 7,13 (SD 0,756) dengan nilai terendah 6 dan nilai tertinggi 8 , sedangkan sesudah dilakukan intervensi diperoleh nilai rata-rata pengeloaan diet sebesar 7,80 (SD $0,561)$ dengan nilai terendah 6 dan tertinggi 8. Dari hasil tersebut disimpulkan bahwa. Hasil tersebut menunjukkan adanya peningkatan skor rata-rata pengelolaan diet pada pasien DM sebesar 0,80 . Hasil analisis uji Wilcoxon Rank Test diperoleh nilai $p$ value 0,006. Dengan demikian diterapkan e-diary pada pasien diabetes militus secara bermakna dan signifikan efektif dalam meningkatkan manajemen selfcare pengelolaan diet pada pasien diabetes militus. Pada kelompok kontrol, nilai rata-rata pengelolaan diet pada pasien DM sebelum diterapkan e-diary adalah 6,93 (SD 0,884) dengan nilai terendah 6 dan tertinggi 8 , sedangkan sesudah diperoleh nilai rata-rata pengeloaan diet sebesar 7,07 (SD 0,799) dengan nilai terendah 6 dan nilai tertinggi 9. Hasil tersebut menunjukkan adanya peningkatan skor rata-rata pengelolaan diet pada pasien DM sebesar 0,06 . Hasil analisis uji Wilcoxon Rank Test diperoleh nilai $p$ value 0,157 . Dengan demikian pada kelompok Kontrol pasien diabetes militus, manajemen selfcare melalui pengelolaan diet pada pasien diabetes militus tidak efektif.

\section{PEMBAHASAN}

Smartphone merupakan telepon seluler yang bekerja menggunakan seluruh perangkat lunak sistem operasi berbasis android yang dapat menyajikan fitur-fitur canggih seperti surel (surat elektronik), kemampuan untuk terhubung dengan jaringan atau internet. Penerapan e-diary secara aplikatif merupakan metode yang digunakan untuk meningkatkan pemahaman pasien DM tentang bagaimana pengelolaan DM secara mandiri. Dalam aplikasi tersebut memuat tentang bagaimana mengelola diet yang 
baik, harus dilakukan oleh pasien. Apabila hal ini dilaksanakan dengan baik informasi yang diperoleh akan sangat membantu bagaimana mereka mengelola diabetes militus.

Adanya infromasi yang diperoleh melalui aplikasi e-diary secara langsung juga akan meningkatkan pengetahuan mereka sehingga hal ini juga akan dapat merubah perilaku pasien selama melakukan selfcare manajemen. Hal ini sebagaimana penjelasan Orem bahwa Self-care berfokus pada bagaimana meningkatkan kemampuan klien untuk berperilaku yang dapat mempengaruhi kesehatannya. Kemampuan ini dilakukan sendiri oleh klien yang bertujuan untuk meningkatkan status kesehatan (Sousa et al., 2009)

Penelitian (Bai, Chiou, \& Chang, 2009) menemukan adanya hubungan yang positif antara lama menderita diabetes militus dengan kemampuan selfcare. Mereka yang sudah lama menderita diabetes militus lebih mudah melakukan selfcare manajemen dibandingkan mereka yang belum lama didiagnosa diabetes melitus. Hal ini disebabkan oleh pengalaman yang mereka alami selama menderita DM sehingga lebih mudah memahami semua informasi terkait dengan pengelolaan DM.

Tujuan dari self care sebagaimana dikemukakan oleh (Sousa \& Zauszniewski, 2005) adalah bagaimana penderita DM mampu mengelola diet, latihan jasmani, mengontrol gula darah serta penggunaan anti diabetes sesuai dengan petunjuk pengobatan. Adapun tujuan dari self tersebut telah dimasukan kedalam aplikasi e-diary sehingga apabila hal ini dilaksanakan dengan baik maka pasien akan mampu melaksanakan manajemen selfcare.

Penelitian (Dimas Rizki Nugroho Adi, 2014) tentang aplikasi pengaturan gizi dan diet khusus harian untuk penyakit diabetes mellitus berbasis android. Hasil penelitian tersebut menunjukkan bahwa aplikasi ini dapat menampilkan statistika keadaan gula darah yang diinputkan oleh user setelah menjalankan diet sehingga aplikasi ini dapat membantu pasien Diabetes Mellitus untuk melakukan pengontrolan terhadap keadaan gula darahnya.

Hasil penelitian (Prasetyo, 2016) tentang aplikasi perhitungan kebutuhan zat gizi pada penyakit diabetes mellitus berbasis android menunjukkan bahwa aplikasi perhitungan kebutuhan zat gizi pada penyakit diabetes melitus mendapat respon yang baik sehinnga dapat mempermudahkan kinerja ahli gizi untuk menghitung kebutuhan zat gizi. Dibuktikan dengan hasil riset menggunakan kuisoner yaitu $87 \%$ menilai baik aplikasi tersebut.

\section{SIMPULAN DAN SARAN}

Simpulan

Penelitian ini telah mengidentifikasi beberapa karakteristik dari 30 responden. Usia responden berada pada rentang usia 46-55 tahun dan berpendidikan SMA dan berstatus tidak bekerja serta lama menderita $\mathrm{DM}>2$ tahun. Pada kelompok intervensi diterapkan e-diary pada pasien diabetes militus secara bermakna dan signifikan efektif dalam meningkatkan manajemen selfcare pengelolaan diet.

\section{Saran}

Aplikasi e-diary dapat digunakan sebagai salah satu sarana keilmuan untuk pengembangan intervensi keperawatan khususnya bagaimana meningkatkan pengetahuan pasien sehingga pasien akan lebih mudah menerapakan manajemen selfcare pasien guna mengendalikan kondisi gula darah serta mencegah komplikasi akibat penyakit diabetes militus. 


\section{KEPUSTAKAAN}

American Diabetes Association (ADA). (2015). Standards of Medical Care In Diabetes-2015, 38(January 2015). https://doi.org/10.2337/dc13-S011

American Diabetes Association (ADA). (2017). Standards Of Medical Care In Diabetes - 2017. Diabetes Care, 40(January).

Atak, N., T, G., \& Kose, K. (2013). The Effect of Education on Knowledge, Self Management Behaviours and Self Efficacy of Patients with Type 2 Diabetes. Aust J Adv Nurs (Vol. 26).

Bai, Y.-L., Chiou, C.-P., \& Chang, Y.-Y. (2009). Self-care behaviour and related factors in older people with Type 2 diabetes. Journal of Clinical Nursing, 18(23), 3308-3315. https://doi.org/10.1111/j.13652702.2009.02992.x

Cheryl Holly, EdD, RN, Susan Salmond, EdD, RN, FAAN, Maria Saimbert, PharmD, MLIS, MSN, R. (2010). Comprehensive Systematic Review for Advanced Nursing Practice - Google Buku. Retrieved from https://books.google.co.id/books?id=58NoYuD0hlYC\&pg=PA79\&lpg=PA79\&dq=Ligaray+dan+lsley\& source=bl\&ots=7aU64AdnCd\&sig=JA_MEgVNxOCQOa3UEuyynH3a6-

M\&hl=id\&sa=X\&ved=2ahUKEwiQpLit4trcAhUDP48KHXjfABAQ6AEwAXoECAcQAQ\#v=onepage\&q=Li garay dan Isley\&f=false

Dimas Rizki Nugroho Adi, K. (2014). APLIKASI PENGATURAN GIZI DAN DIET KHUSUS HARIAN UNTUK PENYAKIT DIABETES MELLITUS BERBASIS ANDROID (STUDI KASUS PADA PUSKESMAS WONOSOBO I). Retrieved August 7, 2018, from http://repository.amikom.ac.id/index.php/detail/5117/APLIKASI PENGATURAN GIZI DAN DIET KHUSUS HARIAN UNTUK PENYAKIT DIABETES MELLITUS BERBASIS ANDROID (STUDI KASUS PADA PUSKESMAS WONOSOBO I)

Elliott, J. A., Abdulhadi, N. N., Al-maniri, A. A., Al-shafaee, M. A., \& Wahlstro, R. (2013). Diabetes SelfManagement and Education of People Living with Diabetes: A Survey in Primary Health Care in Muscat Oman, 8(2). https://doi.org/10.1371/journal.pone.0057400

Elly Lilianty Sjattar (https://orcid.org/0000-0002-7376-5771) - Google Scholar Citations. (n.d.-a). PENGARUH DISCHARGE PLANNING TERHADAP SELF CARE BEHAVIOUR PASIEN DIABETES MELLITUS TIPE II DI RUMAH SAKIT BHAYANGKARA MAKASSAR. Retrieved from https://scholar.google.co.id/citations?user=ig_8HTwAAAAJ\&hl=en\#d=gs_md_cita-

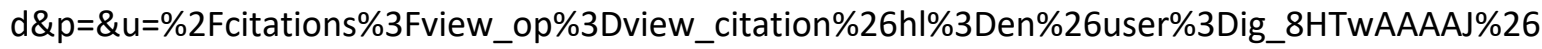
citation_for_view\%3Dig_8HTwAAAAJ\%3AZph67rFs4hoC\%26tzom\%3D-480

Gao, J., Wang, J., Zheng, P., Haardörfer, R., Kegler, M. C., Zhu, Y., \& Fu, H. (2013). Effects of self-care, selfefficacy, social support on glycemic control in adults with type 2 diabetes. https://doi.org/10.1186/1471-2296-14-66

H. Nwankwo, C., Nandy, B., \& O. Nwankwo, B. (2010). Factors Influencing Diabetes Management Outcome among Patients Attending Government Health Facilities in South East, Nigeria. International Journal of Tropical Medicine (Vol. 5). https://doi.org/10.3923/ijtmed.2010.28.36

Kohler-rausch, E. (2014). Education and technology used to improve the quality of life for people with diabetes mellitus type II, 147-153. 
Ma, L., Gu, L., \& Wang, J. (2014). Research and Development of Mobile Application for Android Platform. International Journal of Multimedia and Ubiquitous Engineering, 9(4), 187-198.

Panagioti, M., Richardson, G., Murray, E., Rogers, A., Kennedy, A., Newman, S., ... Bower, P. (2014). Reducing Care Utilisation through Self-management, 2(54). https://doi.org/10.3310/hsdr02540

PERKENI. (2015). Konsensus Pengendalian dan Pencegahan Diabetes Melitus Tipe 2 di Indonesia 2015. Perkeni. https://doi.org/10.1017/CBO9781107415324.004

Prasetyo, E. D. (2016). Aplikasi Perhitungan Kebutuhan Zat Gizi Pada Penyakit Diabetes Berbasis Android.

Sousa, V. D., Hartman, S. W., Miller, E. H., \& Carroll, M. A. (2009). New measures of diabetes self-care agency, diabetes self-efficacy, and diabetes self-management for insulin-treated individuals with type 2 diabetes. Journal of Clinical Nursing, 18(9), 1305-1312. https://doi.org/10.1111/j.13652702.2008.02729.x

Sousa, V. D., \& Zauszniewski, J. A. (2005). Toward a Theory of Diabetes Self-Care Management. Journal of Theory Construction and Testing. Retrieved from https://www.highbeam.com/doc/1P31036335671.html

Sudigdo Sastroasmoro, S. I. (2015). Metodologi Penelitian Klinis. Jakarta: Sagung Seto.

Wattana, C., Srisuphan, W., Pothiban, L., \& Upchurch, S. L. (2007). Effects of a diabetes self-management program on glycemic control, coronary heart disease risk, and quality of life among Thai patients with type 2 diabetes. Nursing \& Health Sciences, 9(2), 135-141. https://doi.org/10.1111/j.14422018.2007.00315.x

Yuan, C., Lai, C. W. K., Chan, L. W. C., Chow, M., Law, H. K. W., \& Ying, M. (2014). The Effect of Diabetes Self-Management Education on Body Weight, Glycemic Control, and Other Metabolic Markers in Patients with Type 2 Diabetes Mellitus, 2014. https://doi.org/10.1155/2014/789761 